\title{
IMIII Race/Ethnicity and Adoption of a Population Health Management Approach to Colorectal Cancer Screening in a Community-Based Healthcare System
}

\author{
Shivan J. Mehta, MD MBA MSHP ${ }^{3}$, Christopher D. Jensen, PhD MPH², Virginia P. Quinn, $P h D M P H^{3}$, \\ Joanne E. Schottinger, MD ${ }^{3}$, Ann G. Zauber, PhD ${ }^{4}$, Reinier Meester, MS ${ }^{5}$, \\ Adeyinka O. Laiyemo, MD MPH', Stacey Fedewa, $\mathrm{MPH}^{7,8}$, Michael Goodman, MD MPH', \\ Robert H. Fletcher, MD MSc9 ${ }^{9}$,Theodore R. Levin, MD², Douglas A. Corley, MD PhD², and \\ Chyke A. Doubeni, MD MPH'
}

\begin{abstract}
'Division of Gastroenterology, Department of Medicine, University of Pennsylvania Perelman School of Medicine, Philadelphia, PA, USA; ${ }^{2}$ Division of Research, Kaiser Permanente, Oakland, CA, USA; ${ }^{3}$ Research \& Evaluation, Kaiser Permanente, Pasadena, CA, USA; ${ }^{4}$ Memorial Sloan Kettering Cancer Center, New York, NY, USA; ${ }^{5}$ Erasmus University Medical Center (Erasmus MC), Rotterdam, Netherlands; ${ }^{6}$ Division of Gastroenterology, Howard University College of Medicine, Washington, DC, USA; 7 Surveillance and Health Services Research, American Cancer Society, Atlanta, GA, USA; ${ }^{8}$ Emory University, Atlanta, GA, USA; ${ }^{~ H a r v a r d ~ M e d i c a l ~ S c h o o l, ~ B o s t o n, ~ M A, ~ U S A ; ~}{ }^{10}$ Department of Family Medicine and Community Health, University of Pennsylvania Perelman School of Medicine, Philadelphia, PA, USA.
\end{abstract}

BACKGROUND: Screening outreach programs using population health management principles offer services uniformly to all eligible persons, but racial/ethnic colorectal cancer (CRC) screening patterns in such programs are not well known.

OBJECTIVE: To examine the association between race/ ethnicity and the receipt of CRC screening and timely follow-up of positive results before and after implementation of a screening program.

DESIGN: Retrospective cohort study of screen-eligible individuals at the Kaiser Permanente Northern California community-based integrated healthcare delivery system (2004-2013).

SUBJECTS: A total of 868,934 screen-eligible individuals 51-74 years of age at cohort entry, which included 662,872 persons in the period before program implementation (2004-2006), 654,633 during the first 3 years after implementation (2007-2009), and 665,268 in the period from 4 to 7 years (2010-2013) after program implementation.

INTERVENTION: A comprehensive system-wide longterm effort to increase CRC that included leadership alignment, goal-setting, and quality assurance through a PHM approach, using mailed fecal immunochemical testing (FIT) along with offering screening at office visits.

MAIN MEASURES: Differences over time and by race/ ethnicity in up-to-date CRC screening (overall and by test type) and timely follow-up of a positive screen. Race/ ethnicity categories included non-Hispanic white, nonHispanic black, Hispanic/Latino, Asian/Pacific Islander, Native American, and multiple races.

KEY RESULTS: From 2004 to 2013, age/sex-adjusted CRC screening rates increased in all groups, including 35.2 to $81.1 \%$ among whites and 35.6 to $78.0 \%$ among

Electronic supplementary material The online version of this article (doi:10.1007/s11606-016-3792-1) contains supplementary material, which is available to authorized users.

Received January 6, 2016

Revised May 16, 2016

Accepted June 17, 2016

Published online July 13, 2016 blacks. Screening rates among Hispanics (33.1 to $78.3 \%$ ) and Native Americans (29.4 to $74.5 \%$ ) remained lower than those for whites both before and after program implementation. Blacks, who had slightly higher rates before program implementation (adjusted rate ratio $[R R]=$ 1.04, 99 \% CI: 1.02-1.05), had lower rates after program implementation (RR for period from 4 to 7 years $=0.97,99$ \% CI: 0.96-0.97). There were also substantial improvements in timely follow-up of positive screening results.

CONCLUSIONS: In this screening program using core PHM principles, CRC screening increased markedly in all racial/ethnic groups, but disparities persisted for some groups and developed in others, which correlated with levels of adoption of mailed FIT.

KEY WORDS: colorectal cancer; cancer screening; population health; health care delivery; race \& ethnicity.

J Gen Intern Med 31(11): 1323-30

DOI: $10.1007 / \mathrm{s} 11606-016-3792-1$

(c) Society of General Internal Medicine 2016

\section{INTRODUCTION}

Colorectal cancer (CRC) remains the second leading cause of cancer death in the United States (US), and disparities persist $^{1}$ despite the availability of proven prevention, early detection, and treatment strategies. ${ }^{2-6}$ National policy groups recommend routine screening for eligible adults using colonoscopy, and sigmoidoscopy and/or high-sensitivity fecal occult blood testing. ${ }^{7}$ National Health Interview Survey data show that $57.8-61.2 \%$ (depending on the analytic approach) of eligible adults were up to date with CRC screening in 2013, overall, ${ }^{8}, 9$ and $60.4 \%$ of non-Hispanic whites, $58.2 \%$ of non-Hispanic blacks, $49.8 \%$ of Asians and $41.5 \%$ of Hispanics were up to date. ${ }^{9}$ Efforts are under way to boost screening uptake to $80 \%$ by $2018 .^{10}$ 
Underutilization of screening in some racial/ethnic groups contributes to disparities in CRC death rates, ${ }^{11-16}$ particularly for blacks, who have the highest CRC mortality rates in the US. ${ }^{17,18}$ These screening disparities may be related to lack of awareness or acceptance, poor patient-physician communication, economic and structural barriers such as lack of health insurance coverage or usual place of medical care. ${ }^{14,}$ 19-23 These barriers may be perpetuated by the traditional opportunistic delivery approach that relies on patient office visits where individual providers order screening tests and encourage adherence. ${ }^{24}$ In contrast, proactive screening programs based on population health management (PHM) principles can provide more uniform services to all eligible persons without relying on face-to-face office visits. ${ }^{24-27}$ These programs have the potential to eliminate disparities in access to and utilization of CRC screening, ${ }^{28}$ but their effectiveness in increasing uptake across diverse groups is unclear. ${ }^{29}$

In 2005, Kaiser Permanente Northern California (KPNC) initiated a more comprehensive long-term effort to increase CRC that included leadership alignment, goal-setting, and quality assurance. This effort was enhanced in 2007, when KPNC implemented a PHM approach, which increased screening rates from 37 to $69 \%$ in the commercially insured and from 41 to $78 \%$ in the Medicare population over the period from 2005 to $2010 .^{24}$ These increases were higher than those reported in the general population of $33.9 \%$ in 2000 to $57.8-61.2 \%$ in $2013 .{ }^{8,9}$ However, the impact of the KPNC program on racial/ethnic disparities has not been examined. This study investigated whether CRC screening uptake, the type of test received, and timely follow-up of positive results after PHM program implementation differed according to race/ethnicity. These results have implications for health systems and policymakers aiming to increase $\mathrm{CRC}$ screening rates in defined populations.

\section{METHODS}

\section{Setting}

This was a retrospective cohort study of CRC-screen-eligible persons who were KPNC members during 2004-2013. KPNC is a community-based healthcare delivery system that provides both healthcare and insurance for about 3.8 million members each year. This integrated delivery structure, along with low disenrollment, provides a stable population whose utilization history can be evaluated over lengthy periods of follow-up. Approval for this study was obtained from the institutional review boards at KPNC and the University of Pennsylvania. This study was conducted within the National Cancer Institutefunded Population-based Research Optimizing Screening through Personalized Regimens (PROSPR) consortium. ${ }^{30}$

\section{Study Population}

For this study, individuals were screen-eligible if they were 5175 years of age, had no previous CRC diagnosis, had not undergone colectomy, and were enrolled for at least one full calendar year between January 1, 2004, and December 31, 2011 (Fig. 1). All individuals were followed using electronic data until December 31st of 2013, CRC diagnosis, age $>75$ years, disenrollment from KPNC, or death, whichever came first.

\section{Data Sources}

Data for the study were obtained from electronic clinical, administrative, vital status, and US Census Bureau data. CRC diagnosis information was obtained from tumor registry data. ${ }^{31}$ CRC tests were identified using Current Procedural Terminology (CPT) and International Classification of Diseases, Ninth Revision, Clinical Modification (ICD-9-CM) codes from electronic data. The results of guaiac fecal occult blood tests (gFOBT)/FIT were obtained from laboratory databases. FIT kit mail dates were obtained from the screening program databases through December 2012 and were used to define a subset of tests completed following program outreach activities.

\section{Population Health Intervention}

KPNC began sigmoidoscopy and stool-based screening in the 1960s as part of health checkups. ${ }^{24}$ In 1994, they began a more robust region-wide screening program focused on using flexible sigmoidoscopy as the primary screening approach, but relied on physician referrals during face-to-face office visits. ${ }^{32,}{ }^{33}$ The program succeeded in screening only one-third of the populations eligible for screening. In response, KPNC initiated a more comprehensive long-term effort that included 1) leadership alignment and accountability for CRC performance goals and targets at each center; 2) performance-based financial allocation; 3) automated electronic medical record (EMR) prompts; 4) moving away from sigmoidoscopy in favor of colonoscopy, while simultaneously increasing capacity through process improvements for both primary screening and diagnostic testing for positive fecal immunochemical tests (FIT); and 5) detailed quality assurance metrics for the entire screening process. ${ }^{24,}{ }^{34} \mathrm{In}$ 2007, KPNC launched a proactive CRC screening program based on PHM principles. This included a dedicated management team that systematically identified all persons $50-75$ years of age who were not up to date on screening during each calendar year, mailed FIT outreach kits to their home addresses (outreach), and automated EMR reminder alerts to offer screening during clinic visits (facilitated in-reach). The program provides information about $\mathrm{CRC}$ screening and instructions for completing FIT in both the mailed kit and on a website dedicated to the screening program. Non-responders are reminded by phone or mail.

\section{Outcomes}

The primary outcome was the receipt of CRC testing for each calendar year, defined as being up to date by use of any of the US Preventive Services Task Force-recommended screening 


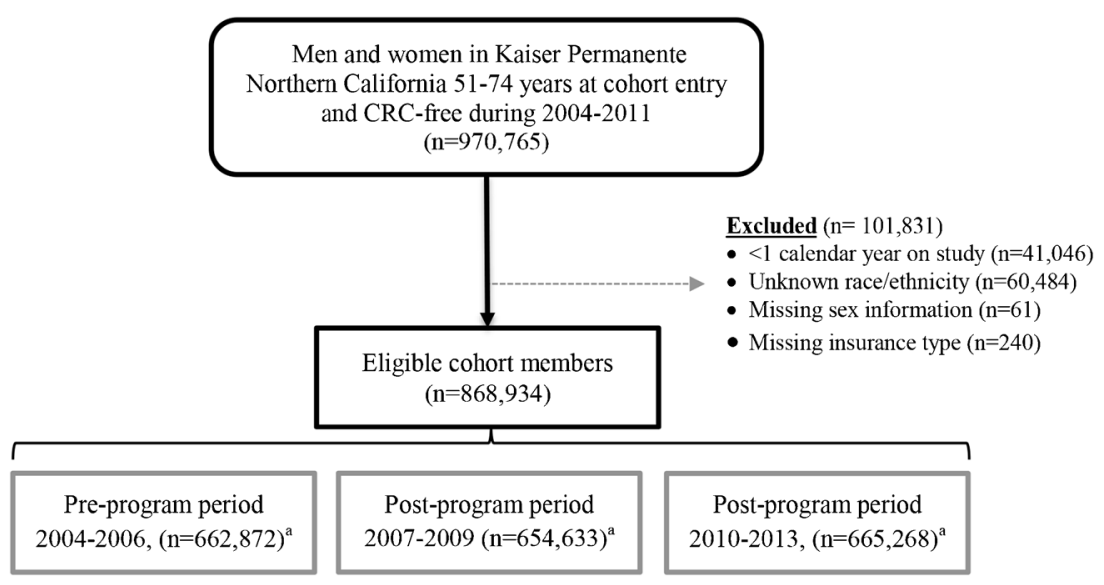

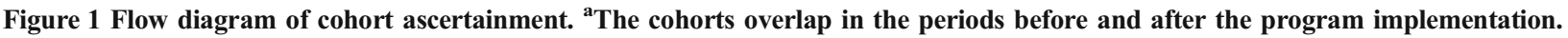

tests, based on Healthcare Effectiveness Data and Information Set (HEDIS) criteria. ${ }^{35}$ Persons $51-75$ years old were considered up to date if, in any given year, they had received a colonoscopy within the prior 10 years, sigmoidoscopy within the prior 5 years, or gFOBT/FIT in that calendar year, without regard to the indication for the test. In 2004, about $79.8 \%$ of individuals had at least 5 years of follow-up (or look-back) prior to cohort entry. Separate secondary outcome measures evaluated receipt of individual CRC tests (colonoscopy, sigmoidoscopy, gFOBT, or FIT). Individuals were also credited as receiving gFOBT/FIT during a calendar year if they had received gFOBT/FIT in the last 91 days of the prior year. ${ }^{36} \mathrm{We}$ defined timely follow-up of positive gFOBT/FIT over the study period as receipt of colonoscopy within 90 days of the positive result, based partially on KPNC quality standards and on published literature. ${ }^{37,38}$

\section{Predictor and Other Variables}

The analysis included people who self-identified or were assigned by an observer as non-Hispanic white (white), nonHispanic black (black), Hispanic/Latino (Hispanic), Asian/ Pacific Islander (API), Native American, or multiple races, and excluded 'other unspecified, or unknown race. Data included age at the date of cohort entry (and updated for each period), sex, insurance (Medicaid, Medicare, or commercial), modified Charlson comorbidity score, ${ }^{39}$ and geographical region where a person received the majority of their care (medical center). Socioeconomic status (SES) was measured using the percentage of households in the census tract who were below the federal poverty level, as this indicator was found to be correlated with CRC test use in previous studies. ${ }^{40}$ We used data from the 2000 decennial census for the 2004-2006 period, and 2006-2010 5-year estimates from the American Community Surveys for the 2007-2013 period.

\section{Statistical Analysis}

We first computed the percentage of persons who were up to date on CRC screening, overall and by test type, separately for each year of the study and by race/ethnicity. We also assessed the percentage of persons who completed FIT after being mailed a FIT kit and the percentage receiving colonoscopy after a positive FIT, according to race/ethnicity. We obtained and compared age/sex-adjusted rates (and $99 \% \mathrm{CI}$ ) for each study year using log-binomial models. We then used logistic regression models to compare screening status in the 3-year period immediately prior (2004-2006) to the immediate postimplementation period (2007-2009) and then to the period 4 to 7 years (2010-2013) after program implementation. We derived the estimates of the rate ratios (RR) and $99 \% \mathrm{CI}$ for the association between race/ethnicity and receipt of screening compared with non-receipt, using predicted values from a model which included an interaction term between race/ethnicity and an indicator for the three time periods. Our regressions used a generalized estimating equation (GEE) approach to account for the correlation of repeated measures in the same individual over time. We compared the magnitude of the RR for each racial/ethnic group (vs. whites) between the pre-implementation (2004-2006) and post-implementation periods using the chi-Square test. Multivariable analyses were adjusted for age, sex, Charlson comorbidity score, insurance type and medical region. Adjustment for SES produced no substantive change in the results and was thus not included in the final models.

We evaluated the receipt of colonoscopy within 90 and 180 days of a positive stool test by racial/ethnic group during the study period. Due to the large sample size, all statistical significance was defined by a $p$ value of 0.01 , and all $p$ values were Bonferroni-adjusted to account for the relevant multiple comparisons. All analyses were performed using STATA version 12.1 software (StataCorp LP, College Station, TX).

\section{RESULTS}

\section{Study Sample}

There were 970,765 potentially eligible men and women aged 51-74 years enrolled in KPNC between 2004 
and 2011. After exclusions, 868,934 eligible persons were included in the analysis (Fig. 1): 662,872 in the cohort before program implementation (2004-2006), 654,633 immediately after implementation (20072009), and 665,268 in the cohort of the last four study years (2010-2013). The study population was $61.0 \%$ white, $8.1 \%$ black, $12.8 \%$ Hispanic, $13.4 \%$ API, $0.5 \%$ Native American, and $4.2 \%$ of multiple races (Table 1).

\section{Screening Utilization Patterns}

The overall age/sex-adjusted proportion of the eligible KPNC population who were up to date on CRC screening increased over the 10-year period, from $35.3 \%$ in 2004 to $80.9 \%$ in 2013 (see online Appendix Table 3, and Fig. 3) with large increases observed in all racial/ ethnic groups (Fig. 2). While increases in all groups were evident in the period preceding implementation of the FIT-based PHM program (2004-2006), the most notable gains in screening were observed after implementation. However, screening rates before and after program implementation remained lowest among Hispanics (from 2004 to 2013: 33.1 to $78.3 \%$ ) and Native Americans (29.4 to $74.5 \%$ ), and highest among APIs (36.3 to $83.0 \%)$ and those of multiple races (39.0 to $84.9 \%$; online Appendix Table 3, Fig. 4). There was a pronounced increase in stool-based test use after program implementation $(4.3 \%$ in 2004 vs. $44.1 \%$ in 2013), along with a transition from gFOBT to FIT (see Fig. 2). The proportion of the population who received colonoscopy increased for all groups over the study period (8.2\% in 2004 vs. $32.6 \%$ in 2013). A decrease was observed in sigmoidoscopy use after program implementation in all groups, but blacks had the slowest rate of decline.

Table 1 Characteristics of the Study Cohort Before and After Screening Program Implementation

\begin{tabular}{|c|c|c|c|}
\hline Characteristics (\%) & $\begin{array}{l}\text { Pre-program (2004-2006) } \\
n=662,872\end{array}$ & $\begin{array}{l}\text { Post-program (2007-2009) } \\
n=654,633\end{array}$ & $\begin{array}{l}\text { Post-program } \\
(2010-2013) \\
n=665,268\end{array}$ \\
\hline \multicolumn{4}{|l|}{ Age (years) } \\
\hline $50-55$ & 54.8 & 35.7 & 34.8 \\
\hline $56-60$ & 15.6 & 25.8 & 24.6 \\
\hline $61-65$ & 12.2 & 16.1 & 17.5 \\
\hline $66-70$ & 10.6 & 12.2 & 12.9 \\
\hline $71-75$ & 6.8 & 10.3 & 10.1 \\
\hline \multicolumn{4}{|l|}{ Race and ethnicity } \\
\hline Non-Hispanic white & 63.1 & 60.9 & 59.4 \\
\hline Non-Hispanic black & 7.9 & 8.1 & 8.2 \\
\hline Hispanic & 11.5 & 12.5 & 13.3 \\
\hline Asian/Pacific Islander & 12.6 & 13.7 & 14.4 \\
\hline Native American & 0.5 & 0.5 & 0.5 \\
\hline Multiple-race & 4.5 & 4.3 & 4.1 \\
\hline Female & 54.1 & 54.1 & 54.6 \\
\hline \multicolumn{4}{|c|}{ Charlson comorbidity score } \\
\hline 0 & 73.4 & 75.7 & 76.9 \\
\hline 1 & 21.5 & 19.9 & 19.0 \\
\hline 2 & 3.8 & 3.3 & 3.1 \\
\hline $3+$ & 1.3 & 1.1 & 1.0 \\
\hline \multicolumn{4}{|c|}{ Enrollment in KPNC (years) } \\
\hline $2-4$ & 10.7 & 4.4 & 15.5 \\
\hline $5-9$ & 35.0 & 47.1 & 41.2 \\
\hline $10+$ & 54.2 & 48.6 & 43.3 \\
\hline \multicolumn{4}{|c|}{ Follow-up in the study (years)* } \\
\hline 1 & 0.3 & 0.4 & 0.5 \\
\hline $2-4$ & 13.9 & 11.6 & 20.8 \\
\hline $5-10$ & 85.8 & 87.9 & 78.7 \\
\hline \multicolumn{4}{|l|}{ Insurance } \\
\hline Medicaid & 0.7 & 0.7 & 0.8 \\
\hline Medicare & 34.8 & 23.4 & 16.3 \\
\hline Commercial & 64.5 & 75.9 & 82.8 \\
\hline \multicolumn{4}{|c|}{$\%$ Household income below federal poverty level (quintiles) ${ }^{\dagger}$} \\
\hline 1 & 20.9 & 21.0 & 21.1 \\
\hline 2 & 20.4 & 20.7 & 20.7 \\
\hline 3 & 19.9 & 20.2 & 20.3 \\
\hline 4 & 19.4 & 19.5 & 19.5 \\
\hline 5 & 18.4 & 18.4 & 18.3 \\
\hline Missing & 0.9 & 0.2 & 0.2 \\
\hline
\end{tabular}

There were 868,934 screen-eligible individuals who were 51-74 years old at cohort entry, had been members of KPNC with at least 1 calendar year of follow-up during the observation period, and did not have a history of colorectal cancer or colectomy prior to cohort entry

*This is the length of time a patient was observed throughout the entire study period

${ }^{+}$Measures were at the census tract level; for the 2004-2006 period they were from the 2000 decennial census, and measures for the 2007-2013 period were derived from the 2006-2010 5-year American Community Survey data from the US Census 


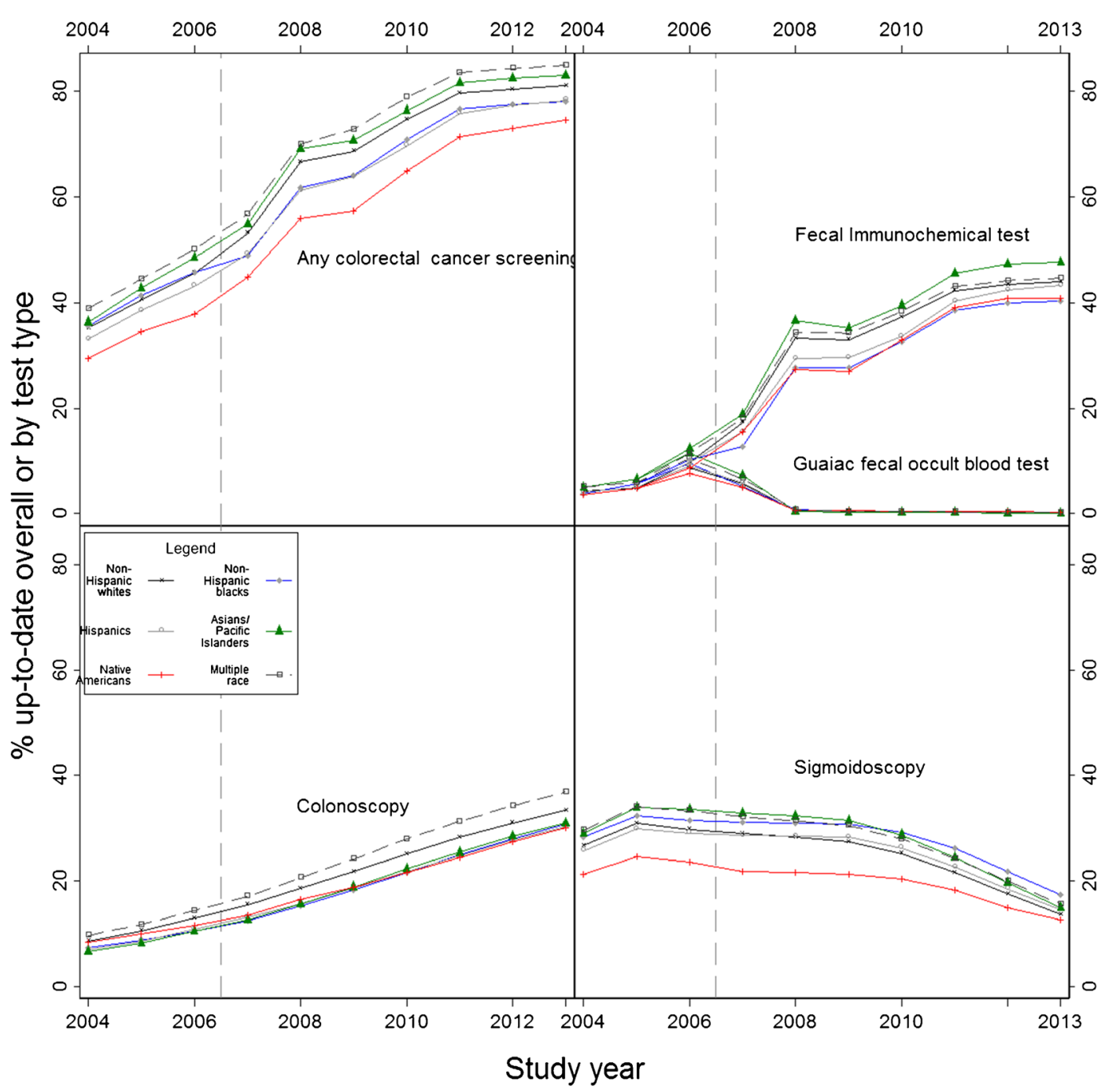

Figure 2 Trend in the proportion of persons in each racial/ethnic group with up-to-date status on colorectal cancer screening, KPNC $2004-2013$. Note: Screening receipt was defined as being up to date by the use of any (in the case of overall rate) of the US Preventive Services Task Forcerecommended tests using the HEDIS criteria, defined separately for each calendar year. Patients were considered up to date on CRC screening if they had received colonoscopy within the prior 5 years, sigmoidoscopy within the prior 5 years, or gFOBT or FIT in each calendar year, without regard to the indication for the test. The vertical line on the $x$-axis demarcates full implementation of the outreach screening program.

\section{Screening After a Mailed FIT Kit and Receipt of Colonoscopy After Positive Stool Test}

Among persons who were sent at least one mailed FIT kit during 2007-2012, the percentage subsequently completing FIT (mailed-FIT completion rate) was highest among multiple-race individuals $(72.6 \%)$, followed by APIs $(68.3 \%)$, whites $(65.5 \%)$, Hispanics $(59.3 \%)$, and blacks $(58.5 \%)$, and was lowest in Native Americans $(56.5 \%$ ) (see online Appendix Table 4). These results paralleled the percentages in each racial/ethnic group who had received FIT during the study. Among those who had a positive stool test, rates of colonoscopy within 90 days increased from $29.8 \%$ in 2004 to $81.1 \%$ in 2012, with a consistent increase across all racial/ethnic groups. Rates of colonoscopy within 180 days increased from $35.2 \%$ in 2004 to $85.1 \%$ in 2012.

\section{Association between Race/Ethnicity and Overall CRC Screening}

In age/sex-adjusted analyses, compared to the 3-year period (2004-2006) prior to program rollout, screening uptake was 1.60 -fold $(\mathrm{RR}=1.60,99 \% \mathrm{CI}: 1.59-1.60)$ higher in the 3 years following implementation (2007-2009) and was 2.05 -fold $(\mathrm{RR}=2.05,99 \% \mathrm{CI}: 2.04-2.05)$ higher in the period 4 to 7 years (2010-2013) after implementation.

In multivariable analyses, blacks were slightly more likely to be up to date with screening than whites before the program began $(\mathrm{RR}=1.04,99 \% \mathrm{CI}: 1.02-1.05)$, but less likely to be up to date during the first 3 years after implementation ( $R R=$ 0.94, $99 \%$ CI: 0.93-0.95), and the difference narrowed 4 to 7 years after program implementation $(\mathrm{RR}=0.97,99 \% \mathrm{CI}$ : 0.96-0.97) (Table 2, Fig. 3). Among the other racial/ethnic groups, Hispanics had $6 \%$ lower screening rates than whites before program implementation ( $\mathrm{RR}=0.94,99 \% \mathrm{CI}$ : $0.93-$ 
Table 2 Association Between Race/Ethnicity and Being Up to Date on Colorectal Cancer Screening Before and After Outreach Program Implementation, KPNC 2004-2013*

\begin{tabular}{|c|c|c|c|}
\hline \multirow{3}{*}{ Race/ethnicity by screening type } & \multicolumn{2}{|c|}{ Rate ratio (99\% confidence intervals) } & \\
\hline & \multirow[t]{2}{*}{ Pre-program (2004-2006) } & \multicolumn{2}{|c|}{ Post-program implementation } \\
\hline & & $(2007-2009)$ & (2010-2013) \\
\hline \multicolumn{4}{|l|}{ Any CRC test } \\
\hline Non-Hispanic white & 1.00 (ref) & 1.00 (ref) & 1.00 (ref) \\
\hline Non-Hispanic black & $1.04(1.02-1.05)$ & $0.94(0.93-0.95)$ & $0.97(0.96-0.97)$ \\
\hline Hispanic & $0.94(0.93-0.96)$ & $0.92(0.92-0.93)$ & $0.95(0.95-0.96)^{\dagger}$ \\
\hline Asian/Pacific Islander & $1.05(1.04-1.06)$ & $1.03(1.02-1.03)$ & $1.02(1.02-1.02)$ \\
\hline Native American & $0.88(0.83-0.93)$ & $0.87(0.84-0.90)^{\dagger}$ & $0.91(0.89-0.93)^{\dagger}$ \\
\hline Multiple-race & $1.11(1.09-1.13)$ & $1.07(1.06-1.08)$ & $1.05(1.05-1.06)$ \\
\hline \multicolumn{4}{|l|}{ Colonoscopy } \\
\hline Non-Hispanic white & 1.00 (ref) & 1.00 (ref) & 1.00 (ref) \\
\hline Non-Hispanic black & $0.87(0.83-0.90)$ & $0.87(0.85-0.89)$ & $0.93(0.92-0.95)$ \\
\hline Hispanic & $0.77(0.75-0.80)$ & $0.81(0.79-0.83)$ & $0.86(0.85-0.87)$ \\
\hline Asian/Pacific Islander & $0.77(0.74-0.79)$ & $0.82(0.80-0.84)$ & $0.89(0.88-0.90)$ \\
\hline Native American & $0.98(0.85-1.10)$ & $0.91(0.83-0.99)$ & $0.89(0.83-0.95)$ \\
\hline Multiple-race & $1.09(1.05-1.14)$ & $1.08(1.05-1.11)$ & $1.08(1.05-1.10)$ \\
\hline \multicolumn{4}{|l|}{ Sigmoidoscopy } \\
\hline Non-Hispanic white & 1.00 (ref) & 1.00 (ref) & 1.00 (ref) \\
\hline Non-Hispanic black & $1.07(1.05-1.09)$ & $1.11(1.09-1.13)$ & $1.22(1.19-1.24)$ \\
\hline Hispanic & $0.98(0.97-1.00)$ & $1.03(1.02-1.05)$ & $1.09(1.07-1.11)$ \\
\hline Asian/Pacific Islander & $1.09(1.07-1.11)$ & $1.12(1.11-1.14)$ & $1.12(1.10-1.14)^{\dagger}$ \\
\hline Native American & $0.82(0.76-0.89)$ & $0.80(0.74-0.86)^{\dagger}$ & $0.86(0.78-0.95)^{\dagger}$ \\
\hline Multiple-race & $1.12(1.10-1.15)$ & $1.12(1.10-1.15)^{\dagger}$ & $1.13(1.09-1.16)^{\dagger}$ \\
\hline \multicolumn{4}{|l|}{ Stool-based tests } \\
\hline Non-Hispanic white & 1.00 (ref) & 1.00 (ref) & 1.00 (ref) \\
\hline Non-Hispanic black & $1.05(1.02-1.08)$ & $0.82(0.81-0.83)$ & $0.92(0.91-0.93)$ \\
\hline Hispanic & $1.00(0.97-1.03)$ & $0.89(0.88-0.90)$ & $0.96(0.95-0.97)^{\dagger}$ \\
\hline Asians-/Pacific Islander & $1.26(1.23-1.29)$ & $1.09(1.07-1.10)$ & $1.09(1.08-1.10)$ \\
\hline Native American & $0.88(0.77-1.00)$ & $0.83(0.79-0.88)^{\dagger}$ & $0.93(0.89-0.97)^{\dagger}$ \\
\hline Multiple-race & $1.27(1.22-1.32)$ & $1.06(1.04-1.08)$ & $1.03(1.01-1.05)$ \\
\hline
\end{tabular}

*Estimates generated separately for each outcome (any colorectal cancer test, colonoscopy only, sigmoidoscopy only, fecal immunochemical test or fecal occult blood test only) using multivariable logistic regressions with a generalized estimating equation approach, adjusting for age, sex, insurance type, geographic region defined by the medical region of care, and modified Charlson comorbidity score (see text), and a program implementation period indicator (2004-2006, 2007-2009, or 2010-2013). The sample sizes are based on those eligible for screening during the analysis period

${ }^{7}$ The relative ratios for this group vs. non-Hispanic whites in the pre-implementation (2004-2006) period was not statistically significant at the Bonferroni-corrected p-value 0.01 level

0.96), and this relationship did not change during the 3 years after implementation $(\mathrm{RR}=0.92,99 \% \mathrm{CI}: 0.92-0.93$; Bonferroni-corrected $p$ value $=1.00)$. A similar overall pattern was observed for Native Americans $(\mathrm{RR}=0.88,99 \% \mathrm{CI}$ : $0.83-0.93)$ before and 3 years after implementation $(\mathrm{RR}=$ 0.87, $99 \%$ CI: 0.84-0.90). APIs had a slightly higher likelihood of being screened than whites both before and after program rollout (see Table 2).

\section{Association Between Race/Ethnicity and Individual Screening Tests}

Compared with whites, all other racial/ethnic groups except for multiple-race individuals were less likely to undergo colonoscopy before and after implementation (see online Appendix Fig. 4). Relative to whites, all other racial/ethnic groups except Native Americans had higher rates of sigmoidoscopy receipt in the post-implementation period. For example, compared with whites, blacks had $7 \%$ and $22 \%$ higher rates of receiving sigmoidoscopy $(\mathrm{RR}=1.07,99 \% \mathrm{CI}: 1.05-1.09$ and $\mathrm{RR}=1.22$, $99 \%$ CI: $1.19-1.24)$ during the 3 years before and 4-7 years after implementation, respectively. For APIs compared with whites, the RR for sigmoidoscopy use increased slightly, from
1.09 (1.07-1.11) to 1.12 (1.10-1.14) (see Table 2). Compared with whites, blacks had a slightly higher rate of gFOBT/FIT use before program implementation $(\mathrm{RR}=1.05$, $99 \% \mathrm{CI}$ : $1.02-$ 1.08), but were significantly less likely to have had gFOBT/FIT testing during the 3 years following the switch from gFOBT to FIT $(\mathrm{RR}=0.82,99 \% \mathrm{CI}: 0.81-0.83)$.

\section{DISCUSSION}

In this longitudinal evaluation of a comprehensive approach to CRC screening at KPNC, we found large and important increases in receipt of CRC screening across all racial/ethnic groups. By 2013, minority groups had rates of $\mathrm{CRC}$ screening much higher than the national screening rate of $60.4 \%$ for non-Hispanics, $58.2 \%$ for blacks, $51.2 \%$ for Asians and $41.5 \%$ for Hispanics. ${ }^{9}$ Importantly, the most dramatic gains were made after implementation of population health management approaches to CRC screening using mailed FIT. While FIT outreach likely played a large role in the observed increases, other elements germane to the population health management approach such as leadership 
alignment, goal-setting, performance-based financial allocation, and increased capacity for colonoscopy that had been implemented prior to FIT program rollout likely helped set the stage for the increase in screening uptake. In addition, and in contrast to other studies, ${ }^{41,} 42$ we also saw improvements in timely receipt of colonoscopy after a positive stool test.

Despite the overall large improvements in all groups, we did not see a reduction in racial/ethnic disparities, and new gaps developed. This finding is similar to national trends showing large gains in CRC screening among all racial and ethnic groups, but rates remaining higher among whites than other groups. ${ }^{9}$ For Hispanics and Native Americans, we found lower relative screening rates than whites throughout the study period. Of concern is the fact that while blacks had slightly higher screening rates than whites at the start of the program, a gap relative to whites was evident in the first year of program implementation (48.8\% vs. $53.2 \%$ in 2007 compared with $45.7 \%$ vs. $45.6 \%$ in 2006 for blacks and whites, respectively; see online Appendix Table 3, Appendix Table 5 and Appendix Fig. 4) that persisted throughout the observed implementation period. These disparities were largely driven by the rate of completion of mailed-FIT screening, suggesting slower adoption of this approach by blacks compared with whites. ${ }^{43}$ Blacks also had a slightly higher rate of gFOBT use at the start, but had lower mailed-FIT completion rates during the post-implementation period. In addition, blacks showed the slowest decrease in rates of receiving sigmoidoscopy, a test that was de-emphasized in the new program.

One explanation for these findings is that although there have been some local efforts to close gaps with racial/ethnic minorities at KPNC, no systematic efforts have been made to culturally tailor the outreach program. In the case of CRC screening, tailored communication and navigator programs have been shown to increase screening rates in underserved racial/ethnic populations. ${ }^{44-46}$ A similar approach could be applied to mailed FIT through engagement with local communities, along with individually tailored navigator programs for those who do not respond to initial outreach and who screen positive. Additionally, a broader strategy of provider engagement through evaluation and goal-setting could help eliminate disparities, even in outreach programs, but requires further study.

A strength of this study was the extended longitudinal follow-up of a large and relatively stable population to systematically track the use of health services over time. KPNC's integrated delivery structure and the implementation of the population health screening program provided a natural experiment with minimal variability in screening delivery. As such, this is a unique setting within which to study the adoption of an innovative cancer screening approach utilizing population health management principles. A limitation of this study is the inability to account for unmeasured factors that may have contributed to some of the observed differences in screening use. There may be incomplete capture of screening histories in electronic data that could contribute to observed differences, particularly for tests such as colonoscopy with long testing intervals. This limitation may have led to underestimation of the proportion screened, particularly in the early study years, but likely had only a minimal effect on the findings. In addition, clinical data such as family history, gastrointestinal symptoms, information-seeking, and provider recommendation were not available to evaluate the reasons for test choices.

This study demonstrates that a combined population health management and outreach approach to screening markedly increased uptake of CRC screening and followup of positive FIT across diverse patient populations. Our findings support the potential for this approach to increase screening use more broadly. ${ }^{47}$ The findings of differential response to the program across distinct population groups underscore the need to closely monitor and evaluate such programs in the early implementation phases for differential uptake across diverse groups in order to address gaps that may emerge. Policymakers should therefore ensure that when novel health delivery interventions are developed, consideration is given to how they may accrue differentially across diverse population groups. If differences are detected, efforts should be made to understand the causes. Findings from such analyses will inform the use of evidence-based delivery approaches most likely to be effective for specific population groups, thus mitigating the potential for disparities to emerge or worsen as new healthcare innovations are implemented.

Corresponding Author: Chyke A. Doubeni, MD MPH; Department of Family Medicine and Community Health University of Pennsylvania Perelman School of Medicine, 3400 Spruce Street, Gates 2 Pavilion, Philadelphia, PA 19104, USA (e-mail: chyke.doubeni@uphs.upenn.edu).

\section{Compliance with Ethical Standards:}

Funder: The study was supported by grants from the National Cancer Institute at the United States National Institutes of Health (\#UO1 CA151736 and \#U54 CA163262).

Prior Presentations: A prior version of this work was presented at the Digestive Disease Week conference on May 6, 2014.

Conflict of Interest: The authors declare that they do not have a conflict of interest.

\section{REFERENCES}

1. Doubeni CA, Corley DA, Zauber AG. Colorectal cancer health disparities and the role of US law and health policy. Gastroenterology. 2016;150(5): 1052-5.

2. Hewitson P, Glasziou $\mathbf{P}$, Watson $\mathbf{E}$, Towler $\mathbf{B}$, Irwig L. Cochrane systematic review of colorectal cancer screening using the fecal occult blood test (hemoccult): an update. Am J Gastroenterol. 2008; 103(6): 1541-9.

3. Atkin WS, Edwards R, Kralj-Hans I, Wooldrage K, Hart AR, Northover JM, et al. Once-only flexible sigmoidoscopy screening in prevention of 
colorectal cancer: a multicentre randomised controlled trial. Lancet. 2010;375(9726): 1624-33.

4. Schoen RE, Pinsky PF, Weissfeld JL, Yokochi LA, Church T, Laiyemo AO, et al. Colorectal-cancer incidence and mortality with screening flexible sigmoidoscopy. N Engl J Med. 2012;366(25):2345-57.

5. Doubeni CA, Weinmann S, Adams K, Kamineni A, Buist DS, Ash AS, et al. Screening colonoscopy and risk for incident late-stage colorectal cancer diagnosis in average-risk adults: a nested case-control study. Ann Intern Med. 2013;158(5 Pt 1):312-20.

6. Nishihara R, Wu K, Lochhead P, Morikawa T, Liao X, Gian ZR, et al. Long-term colorectal-cancer incidence and mortality after lower endoscopy. N Engl J Med. 2013;369(12):1095-105.

7. U.S. Preventive Services Task Force. Screening for colorectal cancer: U.S. Preventive Services Task Force recommendation statement. Ann Intern Med. 2008; 149(9):627-37.

8. Fedewa SA, Goodman M, Flanders WD, Han X, Smith RA, Ward ME, et al. Elimination of cost-sharing and receipt of screening for colorectal and breast cancer. Cancer. 2015;121(18):3272-80.

9. National Center for Health Statistics. Health, United States, 2015: With Special Feature on Racial and Ethnic Health Disparities. Hyattsville, MD.; 2016. Available at: http://www.cdc.gov/nchs/data/hus/hus15.pdf. Accessed 14 June 2016

10. Meester RG, Doubeni CA, Zauber AG, Goede SL, Levin TR, Corley DA, et al. Public health impact of achieving $80 \%$ colorectal cancer screening rates in the United States by 2018. Cancer. 2015.

11. Robbins AS, Siegel RL, Jemal A. Racial disparities in stage-specific colorectal cancer mortality rates from 1985 to 2008. J Clin Oncol Off J Am Soc Clin Oncol. 2012;30(4):401-5.

12. Soneji S, Iyer SS, Armstrong K, Asch DA. Racial disparities in stagespecific colorectal cancer mortality: 1960-2005. Am J Public Health. 2010;100(10): 1912-6.

13. Cooper GS, Koroukian SM. Racial disparities in the use of and indications for colorectal procedures in Medicare beneficiaries. Cancer. 2004;100(2):418-24.

14. Doubeni CA, Laiyemo AO, Reed G, Field TS, Fletcher RH. Socioeconomic and racial patterns of colorectal cancer screening among Medicare enrollees in 2000 to 2005. Cancer Epidemiol Biomark Prev. 2009; 18(8):2170-5.

15. Laiyemo AO, Doubeni C, Pinsky PF, Doria-Rose VP, Bresalier R, Lamerato LE, et al. Race and colorectal cancer disparities: health-care utilization vs different cancer susceptibilities. J Natl Cancer Inst. 2010;102(8):538-46.

16. Samuel CA, Landrum MB, McNeil BJ, Bozeman SR, Williams CD, Keating NL. Racial disparities in cancer care in the Veterans Affairs health care system and the role of site of care. Am J Public Health. 2014;104(Suppl 4):S562-71.

17. Siegel R, Desantis C, Jemal A. Colorectal cancer statistics, 2014. CA Cancer J Clin. 2014;64(2):104-17.

18. Howlader N, Noone AM, Krapcho M, Miller D, Bishop K, Altekruse SF, Kosary CL, Yu M, Ruhl J, Tatalovich Z, Mariotto A, Lewis DR, Chen HS, Feuer EJ, Cronin KA (eds). SEER Cancer Statistics Review, 1975-2013, National Cancer Institute. Bethesda, MD, based on November 2015 SEER data submission, posted to the SEER web site, April 2016. Available at: http://seer.cancer.gov/csr/1975_2013/. Accessed 14 June 2016.

19. Klabunde CN, Schenck AP, Davis WW. Barriers to colorectal cancer screening among Medicare consumers. Am J Prev Med. 2006;30(4):313-9.

20. Wee CC, McCarthy EP, Phillips RS. Factors associated with colon cancer screening: the role of patient factors and physician counseling. Prev Med. 2005;41(1):23-9.

21. Stimpson JP, Pagan JA, Chen LW. Reducing racial and ethnic disparities in colorectal cancer screening is likely to require more than access to care. Health Aff (Millwood). 2012;31(12):2747-54.

22. Liss DT, Baker DW. Understanding current racial/ethnic disparities in colorectal cancer screening in the United States: the contribution of socioeconomic status and access to care. Am J Prev Med. 2014;46(3):228-36.

23. Soneji S, Armstrong K, Asch DA. Socioeconomic and physician supply determinants of racial disparities in colorectal cancer screening. J Oncol Pract. 2012;8(5):e125-34.

24. Levin TR, Jamieson L, Burley DA, Reyes J, Oehrli M, Caldwell C. Organized colorectal cancer screening in integrated health care systems. Epidemiol Rev. 2011;33(1):101-10.

25. Miles A, Cockburn J, Smith RA, Wardle J. A perspective from countries using organized screening programs. Cancer. 2004;101(5 Suppl):1201-13.

26. Madlensky L, Goel V, Polzer J, Ashbury FD. Assessing the evidence for organised cancer screening programmes. Eur J Cancer. 2003;39(12):1648-53.
27. Ioannou GN, Chapko MK, Dominitz JA. Predictors of colorectal cancer screening participation in the United States. Am J Gastroenterol. 2003;98(9):2082-91.

28. Rhoads KF, Patel MI, Ma Y, Schmidt LA. How do integrated health care systems address racial and ethnic disparities in colon cancer? J Clin Oncol. 2015;33(8):854-60.

29. von Wagner C, Baio G, Raine R, Snowball J, Morris S, Atkin W, et al. Inequalities in participation in an organized national colorectal cancer screening programme: results from the first 2.6 million invitations in England. Int J Epidemiol. 2011;40(3):712-8.

30. Tiro JA, Kamineni A, Levin TR, Zheng Y, Schottinger JS, Rutter CM, et al. The colorectal cancer screening process in community settings: a conceptual model for the population-based research optimizing screening through personalized regimens consortium. Cancer Epidemiol Biomark Prev. 2014;23(7): 1147-58.

31. Doubeni CA, Field TS, Buist DS, Korner EJ, Bigelow C, Lamerato L, et al. Racial differences in tumor stage and survival for colorectal cancer in an insured population. Cancer. 2007;109(3):612-20.

32. Palitz AM, Selby JV, Grossman S, Finkler LJ, Bevc M, Kehr C, et al. The Colon Cancer Prevention Program (CoCaP): rationale, implementation, and preliminary results. HMO Pract. 1997;11(1):5-12.

33. Benson VS, Patnick J, Davies AK, Nadel MR, Smith RA, Atkin WS. Colorectal cancer screening: a comparison of 35 initiatives in 17 countries. Int J Cancer. 2008;122(6): 1357-67.

34. Levin TR. TPMG experience in improving colorectal cancer screening rates. A presentation at the California Colorectal Cancer Roundtable, April 26: California Colorectal Cancer Consortium; 2012. Available at: http:// cacoloncancer.org/documents/roundtable/TR\%20Levin\%20-\%20Screening.pdf. Accessed 14 Jun 2016.

35. HEDIS 2015: Healthcare Effectiveness Data and Information Set. Vol. 2, technical specifications for health plans. Washington (DC): National Committee for Quality Assurance (NCQA); 2014. Available at: http:// www.qualitymeasures.ahrq.gov/content.aspx?id=48604. Accessed 14 June 2015.

36. van Roon AH, Goede SL, van Ballegooijen M, van Vuuren AJ, Looman CW, Biermann K, et al. Random comparison of repeated faecal immunochemical testing at different intervals for population-based colorectal cancer screening. Gut. 2013;62(3):409-15.

37. Partin MR, Powell AA, Nugent S, Ordin DL. Colorectal cancer diagnosis improvement project evaluation demonstrates the importance of using multiple measures to track progress toward timeliness goals. J Healthc Qual. 2013;35(3):41-8

38. Partin MR, Burgess DJ, Burgess JF Jr, Gravely A, Haggstrom D, Lillie SE, et al. Organizational predictors of colonoscopy follow-up for positive fecal occult blood test results: an observational study. Cancer Epidemiol Biomark Prev. 2015;24(2):422-34.

39. Deyo RA, Cherkin DC, Ciol MA. Adapting a clinical comorbidity index for use with ICD-9-CM administrative databases. J Clin Epidemiol. 1992;45(6):613-9.

40. Doubeni CA, Jambaulikar GD, Fouayzi H, Robinson SB, Gunter MJ, Field TS, et al. Neighborhood socioeconomic status and use of colonoscopy in an insured population-a retrospective cohort study. PLoS ONE. 2012;7(5):e36392.

41. Baker DW, Brown T, Buchanan DR, et al. Comparative effectiveness of a multifaceted intervention to improve adherence to annual colorectal cancer screening in community health centers: a randomized clinical trial. JAMA Intern Med. 2014;174(8):1235-41.

42. Green BB, Coronado GD. "Benefits" to increase colorectal cancer screening in priority populations. JAMA Intern Med. 2014;174(8):1242-3.

43. Groeneveld PW, Sonnad SS, Lee AK, Asch DA, Shea JE. Racial differences in attitudes toward innovative medical technology. J Gen Intern Med. 2006;21(6):559-63.

44. Percac-Lima S, Grant RW, Green AR, Ashburner JM, Gamba G, Oo S, et al. A culturally tailored navigator program for colorectal cancer screening in a community health center: a randomized, controlled trial. J Gen Intern Med. 2009;24(2):211-7.

45. Lasser KE, Murillo J, Lisboa S, et al. Colorectal cancer screening among ethnically diverse, low-income patients: a randomized controlled trial. Arch Intern Med. 2011;171(10):906-12.

46. Walsh JM, Salazar R, Nguyen TT, Kaplan C, Nguyen L, Hwang J, et al. Healthy colon, healthy life: a novel colorectal cancer screening intervention. Am J Prev Med. 2010;39(1):1-14.

47. Doubeni CA. The impact of colorectal cancer screening on the US population: is it time to celebrate? Cancer. 2014;120(18):2810-3. 